\title{
Detecting Intermediates and Products of Fast Heterogeneous Reactions on Liquid Surfaces via Online Mass Spectrometry
}

\author{
Agustín J. Colussi ${ }^{1, * \mathbb{D}}$ and Shinichi Enami ${ }^{2} \mathbb{C}$ \\ 1 Linde Center for Global Environmental Science, California Institute of Technology, Pasadena, CA 91125, USA \\ 2 National Institute for Environmental Studies, 16-2 Onogawa, Tsukuba 305-8506, Japan; \\ enami.shinichi@nies.go.jp \\ * Correspondence: ajcoluss@caltech.edu; Tel.: +1-626-395-6350
}

Received: 8 January 2019; Accepted: 22 January 2019; Published: 26 January 2019

check for updates

\begin{abstract}
One of the research priorities in atmospheric chemistry is to advance our understanding of heterogeneous reactions and their effect on the composition of the troposphere. Chemistry on aqueous surfaces is particularly important because of their ubiquity and expanse. They range from the surfaces of oceans ( 360 million $\mathrm{km}^{2}$ ), cloud and aerosol drops (estimated at $\sim 10$ trillion $\mathrm{km}^{2}$ ) to the fluid lining the human lung $\left(\sim 150 \mathrm{~m}^{2}\right)$. Typically, ambient air contains reactive gases that may affect human health, influence climate and participate in biogeochemical cycles. Despite their importance, atmospheric reactions between gases and solutes on aqueous surfaces are not well understood and, as a result, generally overlooked. New, surface-specific techniques are required that detect and identify the intermediates and products of such reactions as they happen on liquids. This is a tall order because genuine interfacial reactions are faster than mass diffusion into bulk liquids, and may produce novel species in low concentrations. Herein, we review evidence that validates online pneumatic ionization mass spectrometry of liquid microjets exposed to reactive gases as a technique that meets such requirements. Next, we call attention to results obtained by this approach on reactions of gas-phase ozone, nitrogen dioxide and hydroxyl radicals with various solutes on aqueous surfaces. The overarching conclusion is that the outermost layers of aqueous solutions are unique media, where most equilibria shift and reactions usually proceed along new pathways, and generally faster than in bulk water. That the rates and mechanisms of reactions at air-aqueous interfaces may be different from those in bulk water opens new conceptual frameworks and lines of research, and adds a missing dimension to atmospheric chemistry.
\end{abstract}

Keywords: fast gas-liquid reactions; online electrospray ionization mass spectrometry; heterogeneous atmospheric chemistry

\section{Introduction}

A recent expert report delineated the research priorities in atmospheric chemistry [1]. It called for "developing a stronger understanding of the influences that heterogeneous chemistry exerts on tropospheric composition", "developing the next generation of accurate, sensitive and specific measurement capabilities for atmospheric constituents ... on surfaces", and "identifying and quantifying the individual oxidants in the condensed phase that contribute to toxicity". Together, these issues point to surfaces as significant media in atmospheric chemistry.

"God made the bulk. Surfaces were invented by the devil", Wolfgang Pauli famously said. The definition of a surface itself raises thorny questions: how thick is the layer of atoms or molecules that can be considered the surface of an object, i.e., where does a surface end and the bulk begins? Or, 
on the topic at hand, how air-liquid interfaces behave when probed from the liquid or the airside? These are fundamental questions, to which experimental and theoretical studies have provided answers as varied and conflicting as those of the six blind men about the elephant [2].

The surface of water is prominent because it is everywhere. The interfacial layers of water represent a distinct phase where the density of water drops five orders of magnitude (from $1 \mathrm{~g} \mathrm{~cm}^{-3}$ to $1.7 \times 10^{-5} \mathrm{~g} \mathrm{~cm}^{-3}$ at $300 \mathrm{~K}$ ) in $\sim 1 \mathrm{~nm}$ [3]. This precipitous density gradient at the molecular scale represents a steep slide on which species nevertheless find equilibrium positions according to their properties. Hydrophobic gases, such as hydrocarbons, tend to accumulate at the relatively dry surface rather than immerse in bulk water [4,5], while ions do the opposite. Reactive gases could be depleted so fast by aqueous solutes in interfacial layers that they never reach bulk water. These are key issues that call for educated guesses. One might ask whether the vast information available on the structure of interfacial water, obtained by surface-specific spectroscopic techniques and molecular dynamics calculations, provides useful hints about interfacial chemistry. The caveat is that the temporal and spatial scales of the interfacial structures revealed by spectroscopic techniques may not match those of interfacial reactions. Furthermore, it is fair to say that the relative sparsity of dynamic/kinetic versus structural studies [6,7] is not on par with the importance of interfacial processes [8]. For this reason, we wanted to call attention to our experiments on the kinetics and mechanisms of interfacial reactions, and to some of the results we obtained on some outstanding issues of atmospheric importance.

The objectives of this paper are to validate online pneumatic ionization mass spectrometry (o-PI-MS, a variant of electrospray ionization mass spectrometry, see below) of liquid microjets dosed by reactive gases as a versatile technique to investigate interfacial processes, and to review some significant results obtained by this approach. Validation was considered necessary because it might not be readily apparent that the o-PI-MS technique could be applied to investigate interfacial reactions $[6,9]$. The main reason is that transferring ions from liquids to the gas-phase is a complex phenomenon. In contrast with the monochromatic signals and selection rules of surface-specific spectroscopic techniques, one is confronted with a sequence of events that begins with the nebulization of liquids into microscopic droplets carrying net charges, followed by rapid solvent evaporation, a series of Coulomb explosions, and ends with ion desolvation and their release to the gas-phase [10].

Questions arise about whether it is valid to assign o-PI mass spectra to the products of gas-liquid reactions occurring in the outermost interfacial layers of liquid microjets. For example: (1) are the detected species drawn from the interfacial layers or the bulk of the liquid microjets? and (2) is the chemistry affected by the electric fields required for ion detection? Below, we analyze experiments specifically designed to address these questions. Our approach to studying interfacial processes via o-PI-MS neither is a new idea nor is as farfetched as it might seem. Yamashita and Fenn had already suggested that electrospray ionization mass spectrometry could be used to investigate liquid interfaces in their seminal 1984 paper [11].

\section{Online Mass Spectrometry of Chemical Reactions on Liquid Microjets}

Because our experimental setup and experiments have been described in several publications from our laboratories [12-16], here we focused on their essential features. At the outset, we wish to emphasize that electrospray ionization mass spectrometers are not all alike. Therefore, it is crucial to report the particular configuration of the mass spectrometer used in each case, and the specific experimental conditions under which results were obtained. Key differences are whether the nebulizer is grounded or not, and whether the liquid microjets are directly ejected (along the X-axis) (see Figure 1) towards the inlet orifice in the metal plate (MP) that separates the spraying chamber from the low pressure section of the mass spectrometer, along a perpendicular (Y-axis) direction, or in a Z-configuration [17]. Comparisons of results obtained using different instruments should always bear in mind these issues. 


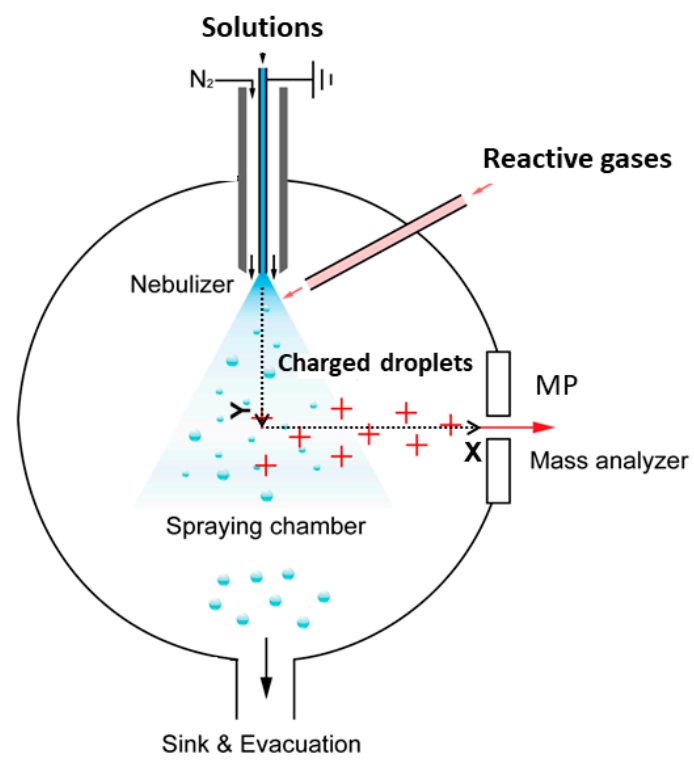

Figure 1. A schematic representation of the electrospray source used in our experiments (See [12-16] for additional details). The spraying chamber is at atmospheric pressure and ambient temperature. MP is a metal plate polarized at $\leq 3.5 \mathrm{kV}$ (relative to the grounded nebulizer) which has a pinhole inlet to the mass analyzer section of the mass spectrometer (not shown).

In our experiments, solutions of diverse solutes in water or its mixtures with fully miscible organic solvents such as acetonitrile, tetrahydrofuran or 1,4-dioxane, were pumped through a grounded stainless-steel syringe injector (100 $\mu \mathrm{m}$ bore). The linear speed of the liquid microjets flowing into the spraying chamber of the mass spectrometer is $\sim 10 \mathrm{~cm} \mathrm{~s}^{-1}$ (chamber at 1 atmosphere and room temperature). Liquid microjets were nebulized by a codirectional $\mathrm{N}_{2}(\mathrm{~g})$ flow (at $>100 \mathrm{~m} \mathrm{~s}^{-1}$, through a sheath coaxial with the syringe injector). The large difference between the speeds of the liquid microjet and the nebulizer gas forced the liquid to fragment into fine, electrically charged, primary $\sim 10$ micrometer diameter droplets [18,19] within $\tau \leq 10$ microseconds, as revealed by high-speed photography of the shearing of cylindrical water jets by fast annular gas flows [20-23]. Primary droplets were rapidly blown by the nebulizer gas into liquid "bags", which broke up into secondary, sub-micron size droplets carrying net charges [20]. Experiments have shown that: (1) the thin bag films are enriched in anions, whereas cations accumulate in the thick bag rims, as expected from the higher affinity of the former for the air-water interface [20,24], and (2) the extent of ion segregation (between anions in the films from cations in the rims, and from different anions within the films) increases with nebulizer gas flow rate [15]. Aerodynamic considerations indicate that the smaller (less than $\sim 10$ micrometer) secondary and later generation progeny microdroplets cannot be further deformed by the nebulizer gas. The fate of later generation microdroplets is in fact controlled by the balance of surface tension versus electrostatic repulsion among excess charges (see below). During nebulization, the kinetic energy of the nebulizing gas provides energy for creating the droplets surfaces, and for charging droplets by separating the anions and cations already present in the liquid microjets. The net result is that the gas-liquid sprays issuing from a grounded nozzle injector consist of normal distributions of weakly charged droplets centered at charge zero, as expected from statistical charge separation during the fragmentation of a neutral liquid [25]. It is apparent that the aerodynamic charging process naturally discriminates against the production of highly charged droplets, simply because they would require more energy. Solvent evaporation in the spraying chamber (continuously flushed with dry $\mathrm{N}_{2}(\mathrm{~g})$ ) could lead to droplet shrinkage and concomitant surface charge crowding. Consequently, droplets become mechanically unstable at the point where electric repulsion of interfacial charges overtakes liquid cohesion, thereby triggering Coulomb explosions into smaller droplets. Charged microdroplets are deflected towards the mass analyzer sector by applying an electric bias to the inlet 
port MP. In this sector, charged microdroplets are electrically driven through a heated capillary, where ions are desolvated and released bare to the gas-phase [26]. The preceding description shows that the ions detected by the mass spectrometer are produced from the shearing of the interfacial layers of the liquid microjets, followed by the breakup of primary microdroplets.

That the droplets produced by nebulizing liquids are charged has been known for more than a century [20,21], and has important applications [27]. It is important to realize that droplet charging does not require [28,29], although may be enhanced by the presence of electric fields. Below, we show that in our setup the creation of net charge was mainly due to pneumatic nebulization rather than to the applied electric field. This is the reason why we referred to our technique as online pneumatic ionization mass spectrometry, o-PI-MS. It should be emphasized that, electric fields could participate in droplet charging in other electrospray ion source configurations, and at higher applied voltages.

Because the surface of liquid microjets containing mobile ions is equipotential with the grounded injector, the electric field inside the microjets is null. Applied electric fields, however, induce surface charges of densities determined by the MP voltage and the local curvature of the liquid surface. The sign of surface charges is determined by the voltage polarization, i.e., a MP at positive voltage relative to ground induces negative charges on the surface of microjets, and vice versa. Below, we show that the surface charges induced by the applied electric field played a minimal role, if any, in our experiments.

In a typical experiment, streams of reactive gases, such as $\mathrm{O}_{3}(\mathrm{~g})$ or $\mathrm{NO}_{2}(\mathrm{~g})$, are directed to the liquid microjets as they emerge from the tip of the nebulizer. Some reactions between gases and solutes do occur at the gas-liquid interfaces of the microjets during their $\tau \leq 10 \mu$ s lifetimes [22]. Note that only fast heterogeneous reactions meet such a constraint. This constraint, however, is not as restrictive as it may seem because, remarkably, interfacial reactions have been found to be much faster (up to several orders of magnitude) than estimated from kinetic parameters determined in bulk liquids [14,30-32].

\section{Mass Spectra Reflect the Composition of the Outermost Interfacial Layers of the Liquid Microjets}

The first indication that we sampled the interfacial layers rather than the bulk of the microjets was provided by the mass spectra of equimolar solutions of the sodium salts of a series of anions [33,34]. We found that the mass signal intensities of the various anions were not identical, as would be expected if mass spectra reflected the composition of the bulk equimolar solutions, but rather scaled exponentially with anion radii. This outcome suggested that our experiments probed interfacial layers where anions had fractionated following a Hofmeister series [35]. We obtained more direct, semi-quantitative evidence from other experiments. We will illustrate this with the following examples.

In one set of experiments, liquid microjets of $n$-hexanoic acid (PCOOH, $\mathrm{pK}_{\mathrm{a}}=4.8 ; \mathrm{P}=n$-pentyl) solutions in 1:1 (vol:vol) $\mathrm{H}_{2} \mathrm{O} / \mathrm{D}_{2} \mathrm{O}$ at $\mathrm{pH} 7$ (reported $\mathrm{pH}$ is always of the injected bulk solutions, as measured with a calibrated $\mathrm{pH}$-meter. $\mathrm{pD}=\mathrm{pH}+0.4$ ) were dosed with $\mathrm{HNO}_{3}(\mathrm{~g})$ or $\mathrm{DNO}_{3}(\mathrm{~g})$ streams [36]. Mass spectra in the negative ion mode revealed that $n$-hexanoate $\mathrm{PCOO}^{-}$ion signals $(\mathrm{m} / \mathrm{z}=115)$ decreased and nitrate signals $(\mathrm{m} / \mathrm{z}=62)$ increased upon increasing $\mathrm{HNO}_{3}(\mathrm{~g})$ and $\mathrm{DNO}_{3}(\mathrm{~g})$ flow rates, as expected from the acidification of the media from where these signals originated. In the same experiments, mass spectra in the positive ion mode revealed the presence of hydronated (by $\mathrm{H}^{+}$ or $\left.\mathrm{D}^{+}\right) n$-hexanoic acid $\mathrm{PCOOH}_{2}{ }^{+}(\mathrm{m} / \mathrm{z}=117), \mathrm{PCOOHD}^{+}(\mathrm{m} / \mathrm{z}=118)$ and $\mathrm{PCOOD}_{2}{ }^{+}(\mathrm{m} / \mathrm{z}=119)$ [37]. The key observation was that the relative intensities of the hydronated $\mathrm{PCOOH}$ signals significantly changed upon switching from $\mathrm{HNO}_{3}(\mathrm{~g})$ to $\mathrm{DNO}_{3}(\mathrm{~g})$. From the measured flow rates of the liquid microjets and the $\mathrm{HNO}_{3}(\mathrm{~g}) / \mathrm{DNO}_{3}(\mathrm{~g})$ streams, we estimated that the inflows of $\mathrm{H} / \mathrm{D}$ atoms (atoms s${ }^{-1}$ ) carried by the liquid microjets into the spraying chamber was $>1000$ times larger than those carried by $\mathrm{HNO}_{3}(\mathrm{~g})$ or $\mathrm{DNO}_{3}(\mathrm{~g})$. Therefore, the fact that the isotopic composition of hydronated $\mathrm{PCOOH}$ changed upon switching from $\mathrm{HNO}_{3}(\mathrm{~g})$ to $\mathrm{DNO}_{3}(\mathrm{~g})$ implied that $\mathrm{PCOOH}$ hydronation must have taken place in relatively thin interfacial layers rather than in the bulk liquid. We calculated the thickness $\delta$ of the interfacial layers probed in our experiments from the proton concentrations required to half 
$\mathrm{PCOO}^{-} \mathrm{m} / \mathrm{z}=115$ signals. Such proton concentrations were generated from the flux of protons $n_{H_{+}}$(in protons $\mathrm{cm}^{-2} \mathrm{~s}^{-1}$ ) deposited by $\mathrm{HNO}_{3}(\mathrm{~g})$ in interfacial layers of thickness $\delta$ during $\tau \leq 10 \mu$ s contact times. $n_{H+}$ was evaluated by means of the kinetic theory of gases (see below) by assuming a unitary uptake coefficient, $\gamma \sim 1$, for $\mathrm{HNO}_{3}(\mathrm{~g})$ on the surface of aqueous electrolytes [36]. In this manner, we estimated: $\delta \sim 2 \pm 1 \mathrm{~nm}$, values. Note that $\tau, \gamma$ and $\delta$ were directly correlated, i.e., $\gamma<1, \tau \leq 10 \mu \mathrm{s}$ values would lead to $\delta<2 \pm 1 \mathrm{~nm}$ interfacial layers.

A second piece of evidence was obtained in the competitive protonation versus lithiation of gas-phase trimethylamine TMA(g) on the surface of aqueous microjets containing $100 \mathrm{mM} \mathrm{LiCl}$ at various $\mathrm{pH}$ values [38]. Plots of the intensities of $\mathrm{TMAH}^{+}(\mathrm{m} / \mathrm{z}=60)$ and $\mathrm{TMALi}^{+}(\mathrm{m} / \mathrm{z}=66)$ signals as functions of $\mathrm{TMA}(\mathrm{g})$ concentration showed that $\mathrm{TMAH}^{+}$signals plateaued above a few parts per million by volume (ppmv) TMA(g) both at $\mathrm{pH} 2.0$ and 3.5, while $\mathrm{TMALi}^{+}$kept increasing up to 150 ppmv TMA(g). These observations signal the presence of a finite pool of protons available to TMA (g) at the gas-liquid interface. This could happen if the available protons were those already present in interfacial layers (rather than in the much larger pool provided by the bulk liquid), and the self-ionization of water were too slow to replenish the interfacial layers with protons within $\sim 10 \mu \mathrm{s}$. In another set of experiments, acidified $\mathrm{D}_{2} \mathrm{O}$ microjets were simultaneously exposed to TMA $(\mathrm{g})$ and $\mathrm{H}_{2} \mathrm{O}(\mathrm{g})$. The detection of TMAD ${ }^{+}$and $\mathrm{TMAH}^{+}$signals of comparable intensities, despite the fact that the inflow of $\mathrm{H}_{2} \mathrm{O}(\mathrm{g})$ was $<\mathrm{D}_{2} \mathrm{O}(\mathrm{l}) / 1000$, provided further evidence that TMA $(\mathrm{g})$ was hydronated in nanoscopic interfacial layers.

Additional evidence was the fact that in most of our heterogeneous ozonation experiments, the mass spectral signals of the reactive solutes $X$ never vanished, even at the highest $\mathrm{O}_{3}(\mathrm{~g})$ concentrations $\left(\sim 100 \mathrm{ppm}, \sim 2 \times 10^{15}\right.$ molecules $\left.\mathrm{cm}^{-3}\right)$, but bottomed out at about half of their initial values $[14,16,31,39]$. This observation implies that our experiments sampled interfacial layers where solutes $\mathrm{X}$ are both consumed by $\mathrm{O}_{3}$, via Equation (1):

$$
\mathrm{X}+\mathrm{O}_{3}=\text { products }
$$

and replenished by diffusion from underlying layers. The thickness of the interfacial layers can be estimated from simple considerations. By assuming that gas-diffusion resistance can be neglected for $\mathrm{O}_{3}(\mathrm{~g})$ approaching microjets of $100 \mu \mathrm{m}$ diameter, the concentrations $\mathrm{N}$ (in molecules cm $\mathrm{cm}^{-3}$ ) of $\mathrm{O}_{3}$ injected into interfacial layers of thickness $\delta$ during contact times $\tau \leq 10 \mu$ s can be evaluated from the kinetic theory of gases, Equation (2):

$$
N=\frac{1}{4 \delta} \gamma c n \tau
$$

In Equation (2), $\gamma \leq 1 \times 10^{-2}$ is the uptake coefficient of $\mathrm{O}_{3}(\mathrm{~g})$ on water [40], $c=3.6 \times 10^{4} \mathrm{~cm} \mathrm{~s}^{-1}$ is the mean thermal speed of $\mathrm{O}_{3}$ molecules and $n$ the concentration of $\mathrm{O}_{3}(\mathrm{~g})$ in molecules $\mathrm{cm}^{-3}$. In typical experiments, solute concentrations dropped by $50 \%$ and bottomed out upon exposure to $n \geq 1 \times 10^{14}$ $\mathrm{O}_{3}$ molecules $\mathrm{cm}^{-3}(\geq 5 \mathrm{ppm})$. Under such conditions: $N \sim 9 \times 10^{10}(1 / \delta)$. The fact that these $\mathrm{O}_{3}$ concentrations could only deplete half of the $1 \mathrm{mM}\left(6 \times 10^{17}\right.$ molecules $\left.\mathrm{cm}^{-3}\right)$ solutes present in interfacial layers, is expressed by Equation (3):

$$
N \sim \frac{9 \times 10^{10}}{\delta}=3 \times 10^{17} \text { molecules } \mathrm{cm}^{-3}
$$

which leads to $\delta \sim 3 \times 10^{-7} \mathrm{~cm}$, i.e., interfacial layers of thickness of a few nanometers.

\section{Products of Gas-Liquid Reactions are Mainly Formed on Liquid Microjets Rather Than on Daughter Microdroplets}

This was demonstrated by the well-defined $\mathrm{RCOO}^{-}(\mathrm{R}=n$-alkyl $)$ mass signals versus $\mathrm{pH}$ titration curves (inflection points at $\mathrm{pK}_{\mathrm{a}}(\mathrm{RCOOH})=4.8$ ) obtained from aqueous $\mathrm{RCOOH}$ solutions $[14,37,38,41-45]$. Well-defined $\mathrm{pK}_{\mathrm{a}}(\mathrm{RCOOH})=4.8$ titration curves imply that the sampled layers have well-defined 
proton activities [46]. given by the $\mathrm{pH}$ values of the injected $\mathrm{RCOOH}$ solutions. Therefore, the sampled layers must be those of the intact microjets or the primary microdroplets, i.e., those from where $\mathrm{RCOO}^{-}$ions are separated from protons $\mathrm{H}^{+}$, before significant solvent evaporation has taken place. In other words, well-defined titration curves exclude later generation microdroplets, which have a broad distribution of (higher) acidities from extensive evaporation, as the source of mass signals.

Further evidence came from experiments involving the ozonolysis of $\beta$-caryophyllene (a very reactive sesquiterpene that adds $\mathrm{O}_{3}(\mathrm{~g})$ within $\left.\sim 10 \mu \mathrm{s}\right)$ in two different configurations. In the first one, microjets of $1 \mathrm{mM} \beta$-caryophyllene solutions in acetonitrile/water mixtures containing $1 \mathrm{mM} \mathrm{NaCl}$ (to bind the neutral $\alpha$-hydroxyhydroperoxide products into detectable chloride adducts) [47] were injected

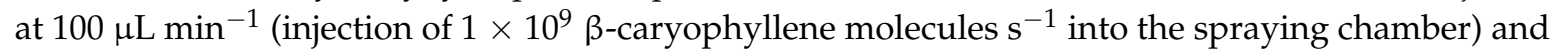
dosed on and off by $\mathrm{O}_{3}(\mathrm{~g})$ streams. Intense mass spectral signals of functional carboxylates (FC, $\mathrm{m} / \mathrm{z}=251)$ and chloride adducts of the $\alpha$-hydroxyhydroperoxides $(\mathrm{HH}, \mathrm{m} / \mathrm{z}=305$ and 307), the products of reactions of the Criegee intermediates generated in the ozonolysis of $\beta$-caryophyllene, appeared upon dosing with $\mathrm{O}_{3}(\mathrm{~g})$. In the second set of experiments, microjets of $1 \mathrm{mM} \mathrm{NaCl}$ in acetonitrile/water solutions (i.e., without $\beta$-caryophyllene) were injected into the spraying chamber simultaneously with $\mathrm{O}_{3}(\mathrm{~g})$ and $\beta$-caryophyllene vapor (at $4 \times 10^{15} \beta$-caryophyllene molecules $\mathrm{s}^{-1}$ ). Although the flow of $\beta$-caryophyllene molecules injected into the spraying chamber in this case was much larger than in the first set of experiments, product signals remained within background noise (Figure S2, Reference 48) [48]. Therefore, in our experiments, products were generated on the surface of intact liquid microjets, rather than on daughter microdroplets or in the gas-phase.

In experiments on the protonation of gas-phase isoprene on acidic $\mathrm{pH} \leq 4$ water microjets, we found that varying the distance from the injector of gas-phase isoprene to the tip of the nebulizer decreased the intensities of product signals. This is again consistent with the protonation of isoprene on intact microjets of well-defined acidities, rather than on superacidic microdroplets [49]. We want to point out that the reactive uptake coefficient of gas-phase isoprene estimated from our experiments on $\mathrm{pH} \leq 3$ water: $5 \times 10^{-7} \leq \gamma_{\mathrm{ISO}} \leq 2 \times 10^{-6}$, is in good accordance with the values reported from independent experiments on acidic $\mathrm{NH}_{4} \mathrm{HSO}_{4} / \mathrm{H}_{2} \mathrm{SO}_{4}$ aerosols: $\gamma_{\mathrm{ISO}}=4 \times 10^{-6}$ [50], and on $70 \%$ $\mathrm{H}_{2} \mathrm{SO}_{4}$ films: $\gamma_{\mathrm{ISO}}=1 \times 10^{-6}[51]$.

\section{Applied Electric Fields Deflected Charged Microdroplets but Did Not Affect Interfacial Chemistry}

Initial evidence that our observations could not be ascribed to electric field effects came from experiments involving the protonation of gas-phase trimethylamine TMA(g) [38] and the deprotonation of gas-phase alkyl-carboxylic acids CA(g) (acetic and hexanoic acids) [52] on the surface of water as a function of bulk pH. In the CA experiments [52], we detected carboxylate anions by polarizing the metal plate MP at positive voltages. In this case, electrostatics dictates that the electric field induces negative surface charge density on the microjets, i.e., an overpopulation of interfacial hydroxide ions $[53,54]$. Therefore, $\mathrm{CA}(\mathrm{g})$ should be deprotonated on the surface of water at $\mathrm{pH}$ values lower than in bulk water. This was indeed the case: half of $\mathrm{CA}(\mathrm{g})$ were deprotonated on the surface of $\mathrm{pH}=2.8$ water, i.e., two $\mathrm{pH}$ units lower than their $\mathrm{pK}_{\mathrm{a}}=4.8$ in bulk water [52]. The same logic predicts that gas-phase TMA should be protonated on the surface of water of $\mathrm{pH}$ values higher than its $\mathrm{pK}_{\mathrm{a}}=9.8$ in bulk water. However, at variance with this prediction, we found that TMA $(\mathrm{g})$ was protonated only on the surface of $\mathrm{pH}<4$ water, i.e., about $10^{6}$ times more acidic than $\mathrm{pH}=9.8$ water [38]. It is apparent that the shifts of the titration curves of both gas-phase acids and bases on the surface of water towards $\mathrm{pH}$ values lower than in bulk water cannot be ascribed to the surface charges induced by the applied electric fields, but correspond to an unrelated phenomenon. In fact, both gas-phase bases and acids being protonated and deprotonated on the surface of water of $\mathrm{pH} \sim 3 \pm 1$ suggests that the underlying mechanism is associated with the properties of interfacial water itself, as we and others have proposed elsewhere [55,56]. 
More direct evidence was obtained from the dependence of the FC $(\mathrm{m} / \mathrm{z}=251)$ and $\mathrm{HH}-\mathrm{Cl}^{-}$ $(\mathrm{m} / \mathrm{z}=305$ and 307$)$ product signal intensities in the ozonolysis of $\beta$-caryophyllene (see Section 4 , above) as functions of the applied polarizing voltage [48]. It was found that signal intensities strictly increased (with a correlation coefficient $\rho^{2}=0.99$ ) with the square root of the polarizing voltage $\mathrm{V}^{1 / 2}$ (see Figure S3 of Reference 48) [48]. This is the dependence of a purely kinematic effect on the trajectories of charged microdroplets in the spraying chamber towards the inlet of the MP (Figure 1), rather than from electric field effects on chemistry.

This follows from simple considerations. In our setup, microdroplets were carried forward (along the Y-axis, Figure 1) by the nebulizer gas at $>100 \mathrm{~m} / \mathrm{s}$ linear speeds. At these speeds, the microdroplets covered the $2 \mathrm{~cm}$ separating the tip of the nebulizer from the x-axis through the inlet in $\tau<0.250$ milliseconds. In order to capture charged microdroplets and detect the ions they carry, an electric field must be applied to deflect them along to the X-axis towards the MP. The instantaneous acceleration $a_{x}$ imposed on the microdroplets by the electric field along the $\mathrm{X}$-axis is given by Equation (4):

$$
\mathrm{a}_{\mathrm{x}}=\left(\frac{\mathrm{ne}}{\mathrm{m}}\right) \frac{\mathrm{V}}{\mathrm{d}}
$$

where ne $\mathrm{e}^{-}$is the charge and $m$ the mass of microdroplets, $\mathrm{V}$ is the potential difference and $d$ the distance between the tip of the grounded nebulizer and MP. As noted above, the mass of microdroplets may not be constant due to continuous solvent evaporation. The net charge of microdroplets, in contrast, only changes in Coulomb explosions upon reaching Rayleigh's thresholds [57]. Therefore, applied voltages $\mathrm{V}$ must be such that the $\Delta \mathrm{x}=1 \mathrm{~cm}$ distance between the $\mathrm{Y}$-axis and the MP is covered by the accelerated microdroplets in $t \leq \tau$ times, Equation (5):

$$
\Delta x=\frac{1}{2}\left(\frac{n e^{-}}{m}\right) \frac{V}{d} t^{2}
$$

i.e., $t \propto \mathrm{V}^{-1 / 2}$. Thus, the shorter the flight times $t$, the larger the number of microdroplets deflected towards the polarized MP, i.e., mass spectral signal intensities should increase as $(1 / t) \propto \mathrm{V}^{1 / 2}$, as observed. We ascribed the stronger $\mathrm{V}^{1 / 2}$ dependence of the $\mathrm{HH}$ signals relative to FC signals (see Figure S3 in Reference 48) to the fact that the neutral $\alpha$-hydroxyhydroperoxides will only bind to $\mathrm{Cl}^{-}$ after microdroplets are desolvated in the mass analyzer section and, therefore, will partially evaporate in the spraying chamber. Hence, evaporation losses of neutral $\alpha$-hydroxyhydroperoxides will be minimized at shorter flight times $t$. The net result is that larger amounts of $\alpha$-hydroxyhydroperoxides will be detected (as $\mathrm{Cl}^{-}$adducts) at shorter $t$ times, an effect that follows the same $\mathrm{V}^{1 / 2}$ dependence and combines with that of the kinematics of microdroplets deflection. Additionally, this analysis shows that mass spectra preferentially reflect the composition of the lighter, more easily deflected microdroplets sheared from the outermost interfacial layers of the microdroplets. The larger inertia of the heavier microdroplets generated from the core of the microjets carries them forward to the bottom of the spraying chamber, and escape detection. In summary, in the configuration of our setup, an electric field must be applied to deflect the charged microdroplets towards the MP. The surface charges induced by these electric fields have a negligible effect on chemistry under the experimental conditions employed.

Below, we summarize some experimental results on gas-liquid reactions involved in key environmental processes. Our studies deal with processes taking place in the outermost interfacial layers of aqueous solutions. Heterogeneous reactions on viscous liquids that cannot be nebulized [58-60], such as those of aged secondary organic aerosols, fall outside the scope of our technique.

\section{Iodide Catalyzes Ozone Oxidations in Marine Aerosols}

A few bromine atoms per trillion have been shown to trigger the fast destruction of ozone in the polar boundary layer in early spring [61]. This phenomenon requires the pre-existence of a significant 
pool ( $\geq 10 \mathrm{pptv}$ ) of Br-containing gas-phase species (photo-Br) that can be rapidly photolyzed into Br-atoms at sunrise. Photo-Br must be produced from seawater $\mathrm{Br}^{-}$, the sole source of bromine in remote regions, by a dark process during polar winters. Our goal was to elucidate the mechanism of the thermal oxidation of marine $\mathrm{Br}^{-}$into photo-Br. The standing hypothesis at the time of our study was that photo-Br was the end-product of the short wavelength photolysis (above the stratospheric ozone layer) of long-lived Br-containing gases, such as biogenic methyl bromide of marine origin and anthropogenic halons. Models based on such an assumption, however, significantly underpredicted field measurements of the proxy BrO radicals [62].

Fine marine aerosol drops, which are highly enriched in $\mathrm{Br}^{-}$and $\mathrm{I}^{-}$ions relative to seawater [63], and remain suspended long enough to undergo significant chemical processing, are likely vehicles for producing photo- $\mathrm{Br}$. We reasoned that the thermal, dark oxidizer had to be $\mathrm{O}_{3}(\mathrm{~g})$. However, the direct oxidation of $\mathrm{Br}^{-}(\mathrm{aq})$ by $\mathrm{O}_{3}(\mathrm{~g})$ into $\mathrm{Br}^{0}$ is a slow reaction: $k\left(\mathrm{Br}^{-}+\mathrm{O}_{3}\right)=248 \mathrm{M}^{-1} \mathrm{~s}^{-1}$, in bulk water [64], A significant clue to the puzzle was the report that more $\mathrm{Br}_{2}(\mathrm{~g})$ is emitted from sea salt than from pure $\mathrm{NaBr}$ upon exposure to $\mathrm{O}_{3}(\mathrm{~g})$. It seemed that the oxidation of $\mathrm{Br}^{-}$ions by $\mathrm{O}_{3}(\mathrm{~g})$ was catalyzed by unidentified components of sea salt [65].

We performed experiments in which we exposed microjets of micromolar $\mathrm{NaI}, \mathrm{NaBr}$ or $\mathrm{NaI}+\mathrm{NaBr}$ solutions to $\mathrm{O}_{3}(\mathrm{~g})$. In the case of NaI, we detected the formation of iodate $\mathrm{IO}_{3}{ }^{-}(\mathrm{m} / \mathrm{z}=175)$ and triiodide $\mathrm{I}_{3}{ }^{-}(\mathrm{m} / \mathrm{z}=381)$ ions, in proportions that depended on solute and gas reactants concentrations. $\mathrm{NaBr}$ solutions under the same conditions did not produce new mass spectral signals, as expected from the low reactivity of $\mathrm{Br}^{-}(\mathrm{aq})$ ions towards $\mathrm{O}_{3}(\mathrm{~g})$. The ozonation of mixed $(\mathrm{NaI}+\mathrm{NaBr})$ solutions, in contrast, led to mass spectra displaying strong signals at $\mathrm{m} / \mathrm{z}=285\left(\mathrm{I}^{79} \mathrm{Br}^{79} \mathrm{Br}^{-}\right), 287\left(\mathrm{I}^{79} \mathrm{Br}^{81} \mathrm{Br}^{-}\right)$ and $289\left(\mathrm{I}^{81} \mathrm{Br}^{81} \mathrm{Br}^{-}\right)$. The presence of two bromines in these trihalide anions meant that at least one of them had to be $\mathrm{Br}^{0}$. In other words, in the presence of $\mathrm{I}^{-}$ions, $\mathrm{Br}^{-}$ions are rapidly oxidized by $\mathrm{O}_{3}(\mathrm{~g})$ at the air-water interface. We inferred that the $\left(\mathrm{I}^{-}+\mathrm{O}_{3}\right)$ reaction generates intermediates that oxidize $\mathrm{Br}^{-}$ ions faster than molecular $\mathrm{O}_{3}$ itself. We hypothesized that the intermediate could be hypoiodous acid $\mathrm{HOI}$, from $\mathrm{O}$-atom transfer to $\mathrm{I}^{-}$ions, or the trioxide $\mathrm{I}_{-} \mathrm{OOO}^{-}$, from $\mathrm{O}_{3}$ addition. Unpublished results from experiments in our laboratory revealed that the latter was the case. A recent $\mathrm{X}$-ray photoelectron spectroscopy study reported the formation of a related $\mathrm{Br}-\mathrm{OOO}^{-}$intermediate [66].

Another key observation was that the depletion of $\mathrm{I}^{-}(\mathrm{aq})$ on the surface of liquid microjets within $\tau \leq 10 \mu$ s was faster than expected from the rate constant $k\left(\mathrm{I}^{-}+\mathrm{O}_{3}\right)=1.2 \times 10^{9} \mathrm{M}^{-1} \mathrm{~s}^{-1}$ in bulk water [64], and the (maximum) $\left[\mathrm{O}_{3}(\mathrm{aq})\right]$ in equilibrium with the $\mathrm{O}_{3}(\mathrm{~g})$ partial pressures $P_{\mathrm{O} 3(\mathrm{~g})}$ used in our experiments: $\left[\mathrm{O}_{3}(\mathrm{aq})\right]=H \mathrm{P}_{\mathrm{O} 3(\mathrm{~g})}\left(\mathrm{H}=1.2 \times 10^{-2} \mathrm{M}\right.$ atm $^{-1}$, is Henry's law constant for $\mathrm{O}_{3}(\mathrm{~g})$ in water at 298K) [67]. The acceleration of reactions at the air-water interface, relative to similar reactions in bulk water, has proven to be a general phenomenon [68]. This is the reason why it is questionable to interpret and "quantify" interfacial processes based on models parametrized with rate constants determined in bulk water. This is also the reason why, at this stage, our approach to interfacial chemistry is empirical, meaning that we focus on the physical implications of the experiments, and rely on semi-quantitative estimates.

A final consideration is that $\mathrm{I}^{-}$ions will outcompete $\mathrm{Br}^{-}$ions for $\mathrm{O}_{3}(\mathrm{~g})$ in marine aerosols, because even though $\mathrm{I}^{-}$ion concentrations are $\sim 10^{-3}$ times smaller than $\mathrm{Br}^{-}$ions [69], $\mathrm{I}^{-}$ions react with $\mathrm{O}_{3}(\mathrm{~g}) 10^{7}$ times faster [64]. In summary, our experiments revealed that $\mathrm{I}^{-}$ions are the "unidentified component of sea salt" that catalyzes the oxidation of $\mathrm{Br}^{-}$ions by $\mathrm{O}_{3}(\mathrm{~g})$ on sea salt and marine aerosol drops. The iodide-catalyzed oxidation of $\mathrm{Br}^{-}$ions by $\mathrm{O}_{3}(\mathrm{~g})$ on the surface of marine aerosols naturally enriched in $\mathrm{Br}^{-}$and $\mathrm{I}^{-}$ions should be a major source of photo-Br in the Arctic boundary layer during the polar night.

\section{The Disproportionation of Nitrogen Dioxide Catalyzed by Anions on Aqueous Aerosols Is the "Unknown Source of Atmospheric Nitrous Acid"}

Modeling the production of the secondary organic aerosol (SOA) has become a major endeavor in tropospheric chemistry. This goal is approached via three-dimensional (3D) transport models that 
include gas/vapor emission strengths, gas-phase chemistry and aerosol microphysics. An implicit assumption common to most studies is that aerosols are a chemical dead end, i.e., once formed they cease to participate in tropospheric chemical cycles. Since "the key to understanding tropospheric chemistry begins with the $\mathrm{OH}$ radical" [70], a critical test for any model is how well it reproduces $\mathrm{OH}$-radical concentrations under diverse conditions. Suggestively, one of the most important shortcomings of current atmospheric chemistry models is their failure to simulate how OH-radical concentrations respond to actinic flux and NOx level variations, and to systematically under-predict atmospheric nitrous acid (HONO) concentrations. Since the rapid $\lambda \leq 395 \mathrm{~nm}$ photolysis of gas-phase $\mathrm{HONO}$ produces $\mathrm{OH}$-radicals with unitary quantum efficiency, Equation (6):

$$
\mathrm{HONO}+\mathrm{h} v(\lambda \leq 395 \mathrm{~nm})=\mathrm{NO}+\cdot \mathrm{OH}
$$

the noted shortcomings point to a mechanistic feature that couples OH-radical and HONO chemistries. What is missing is a strong, yet unidentified, heterogeneous reaction that produces HONO from primary $\mathrm{NO}_{2}(\mathrm{~g})$ emissions at significant rates. This is the problem generally described as the "unknown source of HONO" [71,72]. The consensus is that the mechanism of the "unknown source of HONO" will be revealed by more field measurements with improved instrumentation [72].

The implicit assumption is that the "unknown source of HONO" cannot be the reaction that could produce $\mathrm{HONO}$ from $\mathrm{NO}_{2}$ (g) on aqueous surfaces, such as SOA surfaces in humid air, Equation (7):

$$
2 \mathrm{NO}_{2}+\mathrm{H}_{2} \mathrm{O}=\mathrm{HONO}+\mathrm{NO}_{3}{ }^{-}+\mathrm{H}^{+}
$$

because $\mathrm{NO}_{2}(\mathrm{~g})$ is barely soluble in water (Henry's law constant $=0.01 \mathrm{M} \mathrm{atm}^{-1}$ ) [73], and its uptake coefficient on pure water, $\gamma\left(\mathrm{NO}_{2}\right)_{\mathrm{w}}<1 \times 10^{-7}$ [74], is very small. This argument overlooks the fact that aqueous aerosols are not pure water, but contain significant concentrations of organic and inorganic electrolytes. Defying expectations and prevailing assumptions, we found that the uptake coefficient of $\mathrm{NO}_{2}(\mathrm{~g})$ on the surface of aqueous electrolytes: $\gamma\left(\mathrm{NO}_{2}\right)_{\mathrm{e}}=10^{-3}-10^{-4}$, is orders of magnitude larger than $\gamma\left(\mathrm{NO}_{2}\right)_{\mathrm{w}}$. The underlying process is genuinely interfacial, because $\gamma\left(\mathrm{NO}_{2}\right)_{\mathrm{e}}$ is significantly enhanced by cationic surfactants, weakly depressed by anionic surfactants, and unaffected by hydrophobic 1-octanol [41,75-78]. Significantly, the range of our estimated $\gamma\left(\mathrm{NO}_{2}\right)_{\mathrm{e}}$ values bracket the $\gamma\left(\mathrm{NO}_{2}\right)_{\mathrm{e}}$ $\sim 10^{-4}$ value measured on $\sim 3 \mathrm{mM} \mathrm{NaCl}$ droplets within a cloud chamber in the absence of electric fields $[79,80]$. Our experiments in fact validate the larger $\gamma\left(\mathrm{NO}_{2}\right)_{\mathrm{e}} \sim 10^{-4}$ value on electrolyte solutions vis-à-vis $\gamma\left(\mathrm{NO}_{2}\right)_{\mathrm{W}}<1 \times 10^{-7}$ on pure water, a finding that remained unexplained and consequently ignored by the atmospheric chemistry community. In short, in the presence of dense SOA, such as those developing in midday urban smog, the hydrolytic disproportionation of $\mathrm{NO}_{2}$, Equation (7), may become competitive with the photolysis of $\mathrm{NO}_{2}(\mathrm{~g})$, Equation (8):

$$
\mathrm{NO}_{2}+\mathrm{h} v=\mathrm{NO}+\mathrm{O}\left({ }^{3} \mathrm{P}\right)
$$

thereby switching the source of $\mathrm{OH}$-radicals from the photolysis of $\mathrm{O}_{3}$ (produced from the ground-state $\mathrm{O}\left({ }^{3} \mathrm{P}\right)$ atoms generated the photolysis of $\mathrm{NO}_{2}$, Equation (8)) to the more direct and faster photolysis of $\mathrm{HONO}$. We have shown that our findings may account for the dependences of $\mathrm{NO}_{2}(\mathrm{~g}), \mathrm{HONO}(\mathrm{g})$ and $\mathrm{OH}$-radical concentrations as functions the $\mathrm{J}\left(\mathrm{NO}_{2}\right)$ and $\mathrm{J}(\mathrm{HONO})$ actinic fluxes found in a comprehensive field study [81].

An important corollary is that the existence of alternative photochemical sources of OH-radicals, i.e., $\mathrm{HONO}$ and $\mathrm{O}_{3}$ photolyses, at rates controlled by the competition between $\mathrm{NO}_{2}$ hydrolysis, Equation (7), and $\mathrm{NO}_{2}$ photolysis, Equation (8), as a function of aerosol surface density, should buffer $\mathrm{OH}$-radical concentrations [82]. The buffering of $\mathrm{OH}$-radical concentrations explains the similar values $\left(\tau_{\mathrm{D}}=4 \pm 1 \mathrm{~h}\right.$ ) of the decay lifetimes of $\mathrm{NO}_{2}(\mathrm{~g})$ in urban plumes retrieved from satellite sightings of megacities ranging from Singapore to Moscow at all seasons [82,83]. This is an astonishing finding, 
because it is at odds with the textbook mechanism for the decay of $\mathrm{NO}_{2}(\mathrm{~g})$ into photochemically inert $\mathrm{HNO}_{3}(\mathrm{~g})$ via Equation (9).

$$
\mathrm{NO}_{2}+\cdot \mathrm{OH}(+\mathrm{M})=\mathrm{HNO}_{3}\left(+\mathrm{M}=\mathrm{N}_{2}, \mathrm{O}_{2}\right)
$$

The reason for this is that, since OH-radical concentrations "follow the sun" [84], i.e., they roughly scale with solar irradiance, $\tau_{\mathrm{D}}=\left(k_{5}[\mathrm{OH}]\right)^{-1}$. Therefore, they should significantly increase in winter and at high latitudes. From the perspective gained by our results, a relatively constant $\tau_{D}$ value is consistent with a combination of alternative $\mathrm{NO}_{2}(\mathrm{~g})$ decay processes. $\mathrm{NO}_{2}(\mathrm{~g})$ will decay in part via hydrolysis into $\mathrm{NO}_{3}{ }^{-}$, at rates that depend on aerosol surface area density, or into $\mathrm{HNO}_{3}(\mathrm{~g})$ at rates that scale with buffered $\mathrm{OH}$-radical concentrations.

In summary: our experiments showed that the surfaces of aqueous aerosols could be the substrates of key processes in tropospheric chemistry. Additionally, in all probability, the hydrolysis of $\mathrm{NO}_{2}$, Equation (7), is the "unknown source of HONO". It is unlikely that the "unknown source of HONO" could have been inferred from field campaigns, model parametrizations or theoretical calculations.

\section{Chemistry on the Surface of the Human Lung Is Unusually Selective}

The causality of the adverse effects of air pollution on human health is yet to be established. Numerous epidemiological studies have consistently found positive correlations of cardiovascular $(\mathrm{CV})$ and all-cause (AC) premature mortalities with $\mathrm{O}_{3}$ and $\mathrm{PM}_{2.5}$ (particulates of $<2.5$ micrometer diameter) levels in ambient air [85]. A recent statistical analysis of the most extensive air pollution data and age-specific CV and AC premature mortality rates for 483 counties in 15 US states from 2000 to 2010 confirmed such associations [86]. However, in a key test of causality, the same study showed that the $\sim 30 \%$ decreases of $\mathrm{PM}_{2.5}$ and $\mathrm{O}_{3}$ levels achieved in that period due to the implementation of more stringent emission controls, did not translate into statistically significant changes in premature mortality rates. This is asignificant finding that begets the question of how stringent future regulations on air quality should be in order to achieve tangible improvements. It is apparent that socially optimal levels of control, i.e., those which balance marginal benefits versus the marginal costs of abatement, cannot be designed solely based on epidemiological data alone, but will require information on the detailed chemical and biological mechanisms of the adverse health effects induced by specific air pollutants.

Inhaled oxidants, such as $\mathrm{O}_{3}(\mathrm{~g})$ and $\mathrm{NO}_{2}(\mathrm{~g})$, do not reach the lung tissue, as is generally assumed, because they are scavenged by antioxidants contained in the epithelial fluids (ELFs) lining the respiratory tract. Evidence that adverse health effects do not simply involve local injury to the lung tissue is that inhalation of oxidants pollutants impairs the functions of both heart and lungs within hours. Mortality from acute cardiovascular syndromes markedly increases during episodes of high $\mathrm{O}_{3}$ and $\mathrm{PM}_{2.5}$ levels. This phenomenon strongly suggests a systemic response of the innate immune system to oxidative insult.

The major antioxidant in ELFs is reduced glutathione (GSH, 100-500 $\mu \mathrm{M}$ ), an endogenous tripeptide ( $\gamma$-L-glutamyl-L-cysteinyl-glycine) possessing a $-\mathrm{SH}$ thiol group. The conventional assumption was that the main function of GSH is to scavenge exogenous oxidants into innocuous "ox-GSH" species. The current notion, in contrast, is that GSH do deactivate oxidants; however, the $[\mathrm{GSH}] /[$ "ox-GSH"] ratios generated in ELFs relay the intensity of oxidative stress to the immune system, thereby unleashing systemic responses [87-89]. A nonspecific systemic immune response would be expected if all inhaled oxidants converted GSH to a common "ox-GSH" species. Given the exquisite selectivity of the immune system the issue is, of course, the identity of "ox-GSH" species. It has been long assumed without positive evidence that "ox-GSH" was the disulfide GSSG that would be produced from the recombination of the thiyl GS-radicals ensuing $\mathrm{H}$-abstraction from $\mathrm{S}-\mathrm{H}$ by $\mathrm{OH}$-radicals. 
Reduced glutathione GSH is a diacid that can exist as a mono- or di-anion, depending on the $\mathrm{pH}$. We found that at physiological $\mathrm{pH} \sim 7.5, \mathrm{O}_{3}(\mathrm{~g})$ rapidly oxidizes the dianion $\mathrm{GS}^{2-}$ (aq) (but not the monoanion $\mathrm{GS}^{-}$) to a sulfonate $\mathrm{GSO}_{3}{ }^{-}$rather than to GSSG [90]. Under the same conditions, the oxidation of cysteine (Cys), the S-containing residue in $\mathrm{GSH}$, by $\mathrm{O}_{3}(\mathrm{~g})$ at the air-water interface yields Cys-sulfenic, Cys-sulfinic and Cys-sulfonic acids rather than CySSCy [91]. In more recent experiments, we found that, in contrast with $\mathrm{O}_{3}, \mathrm{OH}$-radicals can oxidize the monoanion $\mathrm{GS}^{-}$(aq). The products are the sulfenic acid GSOH (a weak acid), sulfinate $\mathrm{GSO}_{2}{ }^{-}$and sulfonate $\mathrm{GSO}_{3}{ }^{-}$, from successive $\cdot \mathrm{OH}$ additions to S-atoms, rather than to GSSG from GS-H abstraction [43]. Additionally, we have shown that in the presence of pervasive transition metal ions such as $\mathrm{Fe}^{2+}, \mathrm{O}_{3}(\mathrm{~g})$ can oxidize the monoanion $\mathrm{GS}^{-}$to the same products, via the reactive intermediates generated in fast Fenton-type chemistry at the air-water interface [92].

The relevance of our findings is highlighted by the increasing recognition of the biochemical role of sulfenic and sulfinic acids in regulating the activity of the immune system, such as the promotion of B- and T-cells [93-95]. In hindsight, the reason for the belated awareness of the importance of sulfenic acids was the lack of suitable analytical techniques for their identification and quantitation at the low concentrations they reach in vivo. This fact underscores the power of our technique for identifying novel species down to submicromolar concentrations in complex mixtures.

From a purely chemical point of view, our experiments reveal the extraordinary specificity of . OH for attacking the S-atom of GSH on the surface of water versus its lack of selectivity in bulk water. Such specificity implies an unprecedented steering mechanism during [.OH-GSH] interfacial encounters at the air-water interface, which bypasses the fast, unselective $\mathrm{H}$-abstractions (in bulk water) by $\cdot \mathrm{OH}$ from $\mathrm{S}-\mathrm{H}$ and the multiple $\mathrm{C}-\mathrm{H}$ and $\mathrm{N}-\mathrm{H}$ bonds of $\mathrm{GSH}$. Significantly, our observations are in line with a previous theoretical study on radical recognition and steering mechanism, in which $\cdot \mathrm{OH}$ is captured by GSH carboxylic groups and directed toward the reactive - $\mathrm{SH}$ group by a concerted process involving multiple H-bonded interactions within a flexible GSH framework [96].

\section{Summary}

The novelty and atmospheric relevance of the results obtained by online mass spectrometry underscore its unique advantages over spectroscopic techniques for studying chemistry on liquid surfaces in real time. Online mass spectrometry probes the surfaces of fresh, uncontaminated, fast flowing liquids. It is very sensitive, being able to routinely detect $<1 \mu \mathrm{M}$ ionic species, i.e., at concentrations that are orders of magnitude lower those required by most spectroscopic techniques. Most importantly, mass spectrometry can unambiguously characterize species via their mass-to-charge ratios, thereby dispensing with spectroscopic fingerprints and spectral deconvolution analyses. At this stage of development, it provides semi-quantitative estimates of reactive uptake coefficients and rate constants for interfacial reactions. For all these reasons, online mass spectrometry seems ideally suited for investigating processes at gas-liquid interfaces.

Author Contributions: A.J.C. and S.E. designed experiments. S.E. performed experiments. A.J.C. and S.E. analyzed results and wrote the paper.

Funding: A.J.C. acknowledges support from the National Science Foundation USA, grant AGS-1744353. SE acknowledges support from the JSPS KAKENHI, grant numbers 15H05328 and 15K12188.

Conflicts of Interest: The authors declare no conflict of interest.

\section{References}

1. National Academies of Sciences, Engineering, and Medicine. The Future of Atmospheric Chemistry Research: Remembering Yesterday, Understanding Today, Anticipating Tomorrow; National Academies Press: Washington, DC, USA, 2017.

2. Goldstein, E.B. Encyclopedia of Perception; SAGE Publications: Thousand Oaks, CA, USA, 2010. 
3. Wilson, M.A.; Pohorille, A.; Pratt, L.R. Molecular dynamics of the water liquid-vapor interface. J. Phys. Chem. 1987, 91, 4873-4878. [CrossRef] [PubMed]

4. Donaldson, D.J.; Valsaraj, K.T. Adsorption and reaction of trace gas-phase organic compounds on atmospheric water film surfaces: A critical review. Environ. Sci. Technol. 2010, 44, 865-873. [CrossRef] [PubMed]

5. Valsaraj, K.T. Hydrophobic compounds in the environment-Adsorption equilibrium at the air-water-interface. Water Res. 1994, 28, 819-830. [CrossRef]

6. Ingram, A.J.; Boeser, C.L.; Zare, R.N. Going beyond electrospray: Mass spectrometric studies of chemical reactions in and on liquids. Chem. Sci. 2016, 7, 39-55. [CrossRef] [PubMed]

7. Houle, F.A.; Wiegel, A.A.; Wilson, K.R. Changes in reactivity as chemistry becomes confined to an interface. The case of free radical oxidation of $\mathrm{c}_{30} \mathrm{~h}_{62}$ alkane by OH. J. Phys. Chem. Lett. 2018, 9, 1053-1057. [CrossRef] [PubMed]

8. Burkholder, J.B.; Abbate, J.P.D.; Barnes, I.; Roberts, J.M.; Melamed, M.L.; Ammann, M.; Bertram, A.K.; Cappa, C.D.; Carlton, A.G.; Carpenter, L.J.; et al. The essential role for laboratory studies in atmospheric chemistry. Environ. Sci. Technol. 2017, 51, 2519-2528. [CrossRef] [PubMed]

9. Laskin, J.; Laskin, A.; Nizkorodov, S.A. Mass spectrometry analysis in atmospheric chemistry. Anal. Chem. 2018, 90, 166-189. [CrossRef] [PubMed]

10. Cole, R.B. Electrospray Ionization Mass Spectrometry; Wiley: New York, NY, USA, 1997; p. 571.

11. Yamashita, M.; Fenn, J.B. Electrospray ion source. Another variation on the free-jet theme. J. Phys. Chem. 1984, 88, 4451-4459. [CrossRef]

12. Enami, S.; Colussi, A.J. Long-range specific ion-ion interactions in hydrogen-bonded liquid films. J. Chem. Phys 2013, 138, 184706. [CrossRef]

13. Enami, S.; Colussi, A.J. Criegee chemistry on aqueous organic surfaces. J. Phys. Chem. Lett. 2017, 8, 1615-1623. [CrossRef]

14. Enami, S.; Hoffmann, M.R.; Colussi, A.J. Acidity enhances the formation of a persistent ozonide at aqueous ascorbate/ozone gas interfaces. Proc. Natl. Acad. Sci. USA 2008, 105, 7365-7369. [CrossRef] [PubMed]

15. Enami, S.; Mishra, H.; Hoffmann, M.R.; Colussi, A.J. Hofmeister effects in micromolar electrolyte solutions. J. Chem. Phys 2012, 136, 154707. [CrossRef] [PubMed]

16. Enami, S.; Vecitis, C.D.; Cheng, J.; Hoffmann, M.R.; Colussi, A.J. Mass spectrometry of interfacial layers during fast aqueous aerosol/ozone gas reactions of atmospheric interest. Chem. Phys. Lett. 2008, 455, 316-320. [CrossRef]

17. Manisali, I.; Chen, D.D.Y.; Schneider, B.B. Electrospray ionization source geometry for mass spectrometry: Past, present and future. Trends Anal. Chem. 2006, 25, 243-256. [CrossRef]

18. Kahen, K.; Jorabchi, K.; Gray, C.; Montaser, A. Spatial mapping of droplet velocity and size for direct and indirect nebulization in plasma spectrometry. Anal. Chem. 2004, 76, 7194-7201. [CrossRef] [PubMed]

19. Mabbett, S.R.; Zilch, L.W.; Maze, J.T.; Smith, J.W.; Jarrold, M.F. Pulsed acceleration charge detection mass spectrometry: Application to weighing electrosprayed droplets. Anal. Chem. 2007, 79, 8431-8439. [CrossRef] [PubMed]

20. Zilch, L.W.; Maze, J.T.; Smith, J.W.; Ewing, G.E.; Jarrold, M.F. Charge separation in the aerodynamic breakup of micrometer-sized water droplets. J. Phys. Chem. A 2008, 112, 13352-13363. [CrossRef]

21. Zilch, L.W.; Maze, J.T.; Smith, J.W.; Jarrold, M.F. Freezing, fragmentation, and charge separation in sonic sprayed water droplets. Int. J. Mass Spectrom. 2009, 283, 191-199. [CrossRef]

22. Lasheras, J.; Villermaux, E.; Hopfinger, E. Break-up and atomization of a round water jet by a high-speed annular air jet. J. Fluid Mech. 1998, 357, 351-379. [CrossRef]

23. Theofanous, T.; Li, G. On the physics of aerobreakup. Phys. Fluids 2008, 20, 052103. [CrossRef]

24. Yang, L.; Fan, Y.; Gao, Y.Q. Differences of cations and anions: Their hydration, surface adsorption, and impact on water dynamics. J. Phys. Chem. B 2011, 115, 12456-12465. [CrossRef] [PubMed]

25. Dodd, E.E. The statistics of liquid spray and dust electrification by the Hopper and Laby method. J. Appl. Phys. 1953, 24, 73-80. [CrossRef]

26. Kebarle, P.; Tang, L. From ions in solution to ions in the gas-phase-The mechanism of electrospray mass-spectrometry. Anal. Chem. 1993, 65, A972. [CrossRef]

27. Bailey, A.G. Electrostatic Spraying of Liquids; Research Studies Press: Taunton, Somerset, UK, 1988.

28. Hirabayashi, A.; Sakairi, M.; Koizumi, H. Sonic spray mass-spectrometry. Anal. Chem. 1995, 67, $2878-2882$. [CrossRef] [PubMed] 
29. Pól, J.; Kauppila, T.J.; Haapala, M.; Saarela, V.; Franssila, S.; Ketola, R.A.; Kotiaho, T.; Kostiainen, R. Microchip sonic spray ionization. Anal. Chem. 2007, 79, 3519-3523. [CrossRef] [PubMed]

30. Mondal, S.; Acharya, S.; Biswas, R.; Bagchi, B.; Zare, R.N. Enhancement of reaction rate in small-sized droplets: A combined analytical and simulation study. J. Chem. Phys. 2018, 148, 244704. [CrossRef] [PubMed]

31. Enami, S.; Vecitis, C.D.; Cheng, J.; Hoffmann, M.R.; Colussi, A.J. Global inorganic source of atmospheric bromine. J. Phys. Chem. A 2007, 111, 8749-8752. [CrossRef] [PubMed]

32. Bain, R.M.; Sathyamoorthi, S.; Zare, R.N. "On-droplet" chemistry: The cycloaddition of diethyl azodicarboxylate and quadricyclane. Angew. Chem. Int. Ed. 2017, 56, 15083-15087. [CrossRef]

33. Cheng, J.; Hoffmann, M.R.; Colussi, A.J. Anion fractionation and reactivity at air/water: Methanol interfaces. Implications for the origin of hofmeister effects. J. Phys. Chem. B 2008, 112, 7157-7161. [CrossRef]

34. Cheng, J.; Vecitis, C.; Hoffmann, M.R.; Colussi, A.J. Experimental anions affinities for the air/water interface. J. Phys. Chem. B 2006, 110, 25598-25602. [CrossRef]

35. Wise, P.K.; Ben-Amotz, D. Interfacial adsorption of neutral and ionic solutes in a water droplet. J. Phys. Chem. B 2018, 122, 3447-3453. [CrossRef] [PubMed]

36. Mishra, H.; Enami, S.; Nielsen, R.J.; Hoffmann, M.R.; Goddard, W.A.; Colussi, A.J. Anions dramatically enhance proton transfer through water interfaces. Proc. Natl. Acad. Sci. USA 2012, 109, 10228-10232. [CrossRef]

37. Enami, S.; Stewart, L.A.; Hoffmann, M.R.; Colussi, A.J. Superacid chemistry on mildly acidic water. J. Phys. Chem. Lett. 2010, 1, 3488-3493. [CrossRef]

38. Enami, S.; Hoffmann, M.R.; Colussi, A.J. Proton availability at the air/water interface. J. Phys. Chem. Lett. 2010, 1, 1599-1604. [CrossRef]

39. Enami, S.; Hoffmann, M.R.; Colussi, A.J. Ozonolysis of uric acid at the air/water interface. J. Phys. Chem. B 2008, 112, 4153-4156. [CrossRef] [PubMed]

40. Muller, B.; Heal, M.R. The mass accommodation coefficient of ozone on an aqueous surface. Phys. Chem. Chem. Phys. 2002, 4, 3365-3369. [CrossRef]

41. Enami, S.; Fujii, T.; Sakamoto, Y.; Hama, T.; Kajii, Y. Carboxylate ion availability at the air-water interface. J. Phys. Chem. A 2016, 120, 9224-9234. [CrossRef]

42. Enami, S.; Hoffmann, M.R.; Colussi, A.J. Dry deposition of biogenic terpenes via cationic oligomerization on environmental aqueous surfaces. J. Phys. Chem. Lett. 2012, 3, 3102-3108. [CrossRef]

43. Enami, S.; Hoffmann, M.R.; Colussi, A.J. OH-radical specific addition to glutathione S-atom at the air-water interface: Relevance to the redox balance of the lung epithelial lining fluid. J. Phys. Chem. Lett. 2015, 6, 3935-3943. [CrossRef]

44. Enami, S.; Mishra, H.; Hoffmann, M.R.; Colussi, A.J. Protonation and oligomerization of gaseous isoprene on mildly acidic surfaces: Implications for atmospheric chemistry. J. Phys. Chem. A 2012, 116, 6027-6032. [CrossRef]

45. Cheng, J.; Psillakis, E.; Hoffmann, M.R.; Colussi, A.J. Acid dissociation versus molecular association of perfluoroalkyl oxoacids: Environmental implications. J. Phys. Chem. A 2009, 113, 8152-8156. [CrossRef] [PubMed]

46. Colussi, A.J. Can the $\mathrm{pH}$ at the air/water interface be different from the $\mathrm{pH}$ of bulk water? Proc. Natl. Acad. Sci. USA 2018, 115, E7887. [CrossRef] [PubMed]

47. Zhu, J.; Cole, R.B. Formation and decompositions of chloride adduct ions, $[\mathrm{M}+\mathrm{Cl}]^{-}$, in negative ion electrospray ionization mass spectrometry. J. Am. Soc. Mass Spectrom. 2000, 11, 932-941. [CrossRef]

48. Enami, S.; Colussi, A.J. Chemical signatures of surface microheterogeneity on liquid mixtures. J. Chem. Phys. 2019, 150, 024702. [CrossRef] [PubMed]

49. Ishizuka, S.; Matsugi, A.; Hama, T.; Enami, S. Chain-propagation, chain-transfer, and hydride-abstraction by cyclic carbocations on water surfaces. Phys. Chem. Chem. Phys. 2018, 20, 25256-25267. [CrossRef] [PubMed]

50. Liggio, J.; Li, S.M.; Brook, J.R.; Mihele, C. Direct polymerization of isoprene and alpha-pinene on acidic aerosols. Geophys. Res. Lett. 2007, 34. [CrossRef]

51. Connelly, B.M.; Tolbert, M.A. Reaction of isoprene on thin sulfuric acid films: Kinetics, uptake, and product analysis. Environ. Sci. Technol. 2010, 44, 4603-4608. [CrossRef]

52. Mishra, H.; Enami, S.; Nielsen, R.J.; Stewart, L.A.; Hoffmann, M.R.; Goddard, W.A.; Colussi, A.J. Bronsted basicity of the air-water interface. Proc. Nat. Acad. Sci. USA 2012, 109, 18679-18683. [CrossRef]

53. Chaplin, M. Theory vs experiment: What is the surface charge of water. Water 2009, 1, 1-28. 
54. Beattie, J.K.; Djerdjev, A.N.; Warr, G.G. The surface of neat water is basic. Faraday Discuss. 2009, 141, 31-39. [CrossRef]

55. Colussi, A.J.; Enami, S. Comment on "surface acidity of water probed by free energy calculation for trimethylamine protonation". J. Phys. Chem. C 2014, 118, 2894. [CrossRef]

56. Kallay, N.; Preočanin, T.; Selmani, A.; Kovačević, D.; Lützenkirchen, J.; Nakahara, H.; Shibata, O. Thermodynamic model of charging the gas/water interface. J. Phys. Chem. C 2014, 119, 997-1007. [CrossRef]

57. Rimbert, N.; Castanet, G. Crossover between Rayleigh-Taylor instability and turbulent cascading atomization mechanism in the bag-breakup regime. Phys. Rev. E 2011, 84, 016318. [CrossRef] [PubMed]

58. Davies, J.F.; Wilson, K.R. Nanoscale interfacial gradients formed by the reactive uptake of OH radicals onto viscous aerosol surfaces. Chem. Sci. 2015, 6, 7020-7027. [CrossRef] [PubMed]

59. Heine, N.; Houle, F.A.; Wilson, K.R. Connecting the elementary reaction pathways of criegee intermediates to the chemical erosion of squalene interfaces during ozonolysis. Environ. Sci. Technol. 2017, 51, 13740-13748. [CrossRef] [PubMed]

60. Lee, L.; Wilson, K. The reactive-diffusive length of $\mathrm{OH}$ and ozone in model organic aerosols. J. Phys. Chem. A 2016, 120, 6800-6812. [CrossRef] [PubMed]

61. Simpson, W.; Frieß, U.; Thomas, J.L.; Lampel, J.; Platt, U. Polar nighttime chemistry produces intense reactive bromine events. Geophys. Res. Lett. 2018, 45, 9987-9994. [CrossRef]

62. Schmidt, J.A.; Jacob, D.; Horowitz, H.M.; Hu, L.; Sherwen, T.; Evans, M.J.; Liang, Q.; Suleiman, R.M.; Oram, D.; Le Breton, M. Modeling the observed tropospheric bro background: Importance of multiphase chemistry and implications for ozone, OH, and mercury. J. Geophys. Res. Atmos. 2016, 121. [CrossRef]

63. Duce, R.A.; Hoffman, E.J. Chemical fractionation at air-sea interface. Ann. Rev. Earth Planet. Sci. 1976, 4, 187. [CrossRef]

64. Liu, Q.; Schurter, L.M.; Muller, C.E.; Aloisio, S.; Francisco, J.S.; Margerum, D.W. Kinetics and mechanisms of aqueous ozone reactions with bromide, sulfite, hydrogen sulfite, iodide, and nitrite ions. Inorg. Chem. 2001, 40, 4436-4442. [CrossRef]

65. Mochida, M.; Hirokawa, J.; Akimoto, H. Unexpected large uptake of $\mathrm{O}_{3}$ on sea salts and the observed $\mathrm{Br}_{2}$ formation. Geophys. Res. Lett. 2000, 27, 2629-2632. [CrossRef]

66. Artiglia, L.; Edebeli, J.; Orlando, F.; Chen, S.; Lee, M.-T.; Arroyo, P.C.; Gilgen, A.; Bartels-Rausch, T.; Kleibert, A.; Vazdar, M. A surface-stabilized ozonide triggers bromide oxidation at the aqueous solution-vapour interface. Nat. Commun. 2017, 8, 700. [CrossRef] [PubMed]

67. Sotelo, J.; Beltran, F.; Benitez, F.; Beltran-Heredia, J. Henry's law constant for the ozone-water system. Water Res. 1989, 23, 1239-1246. [CrossRef]

68. Lee, J.K.; Banerjee, S.; Nam, H.G.; Zare, R.N. Acceleration of reaction in charged microdroplets. Q. Rev. Biophys. 2015, 48, 437-444. [CrossRef] [PubMed]

69. Lewis, E.R.; Schwartz, S.E. Sea Salt Aerosol Production: Mechanisms, Methods, Measurements and Models-A Critical Review; American Geophysical Union: Washington, DC, USA, 2004; Volume Geophysical Monograph 152.

70. Seinfeld, J.H.; Pandis, S.N. Atmospheric Chemistry and Physics: From Air Pollution to Climate Change, 2nd ed.; Wiley: Hoboken, NJ, USA, 2006.

71. Spataro, F.; Ianniello, A. Sources of atmospheric nitrous acid: State of the science, current research needs, and future prospects. J. Air Waste Manag. Assoc. 2014, 64, 1232-1250. [CrossRef] [PubMed]

72. Crilley, L.R.; Kramer, L.; Pope, F.D.; Whalley, L.K.; Cryer, D.R.; Heard, D.E.; Lee, J.D.; Reed, C.; Bloss, W.J. On the interpretation of in situ HONO observations via photochemical steady state. Faraday Discuss. 2016, 189, 191-212. [CrossRef] [PubMed]

73. Squadrito, G.L.; Postlethwait, E.M. On the hydrophobicity of nitrogen dioxide: Could there be a "lens" effect for $\mathrm{NO}_{2}$ reaction kinetics? Nitric Oxide 2009, 21, 104-109. [CrossRef]

74. Schwartz, S.E.; Lee, Y.-N. Laboratory study of $\mathrm{NO}_{2}$ reaction with dispersed and bulk liquid water. Atmos. Environ. 1995, 29, 2557-2559. [CrossRef]

75. Enami, S.; Hoffmann, M.R.; Colussi, A.J. Absorption of inhaled NO2. J. Phys. Chem. B 2009, 113, 7977-7981. [CrossRef]

76. Enami, S.; Hoffmann, M.R.; Colussi, A.J. Molecular control of reactive gas uptake "on water". J. Phys. Chem. A 2010, 114, 5817-5822. [CrossRef] 
77. Yabushita, A.; Enami, S.; Sakamoto, Y.; Kawasaki, M.; Hoffmann, M.R.; Colussi, A.J. Anion-catalyzed dissolution of $\mathrm{NO}_{2}$ on aqueous microdroplets. J. Phys. Chem. A 2009, 113, 4844-4848. [CrossRef] [PubMed]

78. Kinugawa, T.; Enami, S.; Yabushita, A.; Kawasaki, M.; Hoffmann, M.R.; Colussi, A.J. Conversion of gaseous nitrogen dioxide to nitrate and nitrite on aqueous surfactants. Phys. Chem. Chem. Phys. 2011, 13, 5144-5149. [CrossRef] [PubMed]

79. Bambauer, A.; Brantner, B.; Paige, M.; Novakov, T. Laboratory study of $\mathrm{NO}_{2}$ reaction with dispersed and bulk liquid water. Atmos. Environ. 1994, 28, 3225-3232. [CrossRef]

80. Novakov, T. Laboratory study of $\mathrm{NO}_{2}$ reaction with dispersed and bulk liquid water-Reply. Atmos. Environ. 1995, 29, 2559-2560. [CrossRef]

81. Sorgel, M.; Regelin, E.; Bozem, H.; Diesch, J.M.; Drewnick, F.; Fischer, H.; Harder, H.; Held, A.; Hosaynali-Beygi, Z.; Martinez, M.; et al. Quantification of the unknown HONO daytime source and its relation to $\mathrm{NO}_{2}$. Atmos. Chem. Phys. 2011, 11, 10433-10447. [CrossRef]

82. Colussi, A.J.; Enami, S.; Yabushita, A.; Hoffmann, M.R.; Liu, W.-G.; Mishra, H.; Goddard, W.A., III. Tropospheric aerosol as a reactive intermediate. Faraday Discuss. 2013, 165, 407-420. [CrossRef] [PubMed]

83. Beirle, S.; Boersma, K.F.; Platt, U.; Lawrence, M.G.; Wagner, T. Megacity emissions and lifetimes of nitrogen oxides probed from space. Science 2011, 333, 1737-1739. [CrossRef] [PubMed]

84. Wennberg, P.O. Atmospheric chemistry-Radicals follow the sun. Nature 2006, 442, 145-146. [CrossRef]

85. Pope, C.A.; Ezzati, M.; Dockery, D.W. Fine particulate air pollution and life expectancies in the united states: The role of influential observations. J. Air Waste Manag. Assoc. 2013, 63, 129-132. [CrossRef]

86. Cox, L.A.; Popken, D.A. Has reducing fine particulate matter and ozone caused reduced mortality rates in the united states? Ann. Epidemiol. 2015, 25, 162-173. [CrossRef]

87. Paulsen, C.E.; Carroll, K.S. Cysteine-mediated redox signaling: Chemistry, biology, and tools for discovery. Chem. Rev. 2013, 113, 4633-4679. [CrossRef] [PubMed]

88. Winterbourn, C.C. Are free radicals involved in thiol-based redox signaling? Free Radic. Biol. Med. 2015, 80, 164-170. [CrossRef] [PubMed]

89. Poole, L.B.; Schöneich, C. Introduction: What We Do and Do Not Know Regarding Redox Processes of Thiols in Signaling Pathways; Elsevier: Amsterdam, The Netherlands, 2015.

90. Enami, S.; Hoffmann, M.R.; Colussi, A.J. Ozone oxidizes glutathione to a sulfonic acid. Chem. Res. Toxicol. 2009, 22, 35-40. [CrossRef] [PubMed]

91. Enami, S.; Hoffmann, M.R.; Colussi, A.J. Simultaneous detection of cysteine sulfenate, sulfinate, and sulfonate during cysteine interfacial ozonolysis. J. Phys. Chem. B 2009, 113, 9356-9358. [CrossRef] [PubMed]

92. Enami, S.; Sakamoto, Y.; Colussi, A.J. Fenton chemistry at aqueous interfaces. Proc. Natl. Acad. Sci. USA 2014, 111, 623-628. [CrossRef] [PubMed]

93. Crump, K.E.; Juneau, D.G.; Poole, L.B.; Haas, K.M.; Grayson, J.M. The reversible formation of cysteine sulfenic acid promotes b-cell activation and proliferation. Eur. J. Immunol. 2012, 42, 2152-2164. [CrossRef] [PubMed]

94. Michalek, R.D.; Nelson, K.J.; Holbrook, B.C.; Yi, J.S.; Stridiron, D.; Daniel, L.W.; Fetrow, J.S.; King, S.B.; Poole, L.B.; Grayson, J.M. The requirement of reversible cysteine sulfenic acid formation for $\mathrm{t}$ cell activation and function. J. Immunol. 2007, 179, 6456-6467. [CrossRef] [PubMed]

95. Roos, G.; Messens, J. Protein sulfenic acid formation: From cellular damage to redox regulation. Free Radic. Biol. Med. 2011, 51, 314-326. [CrossRef]

96. Fiser, B.; Jojart, B.; Csizmadia, I.G.; Viskolcz, B. Glutathione-Hydroxyl radical interaction: A theoretical study on radical recognition process. PLoS ONE 2013, 8, e73652. [CrossRef]

(C) 2019 by the authors. Licensee MDPI, Basel, Switzerland. This article is an open access article distributed under the terms and conditions of the Creative Commons Attribution (CC BY) license (http://creativecommons.org/licenses/by/4.0/). 